\section{rev Psi}

Revista de Psicología (UNLP)

https://revistas.unlp.edu.ar/revpsi

\title{
Arteterapia y antipsiquiatría. El arteterapia como una herramienta de cambio
}

\author{
Yolanda Gómez López \\ Correspondencia \\ yolanda.gl19@hotmail.com \\ Filiaciones institucionales \\ ${ }^{1}$ Universidad Autónoma de Madrid (España)
}

\section{Resumen}

El arte genera espacios de crecimiento, de escucha, de apoyo, de trabajo en red y de organización que hacen posibles los cambios. La antipsiquiatría, a partir de las necesidades y demandas actuales, plantea cambios y mejoras en el sistema de salud mental. La presente investigación explora cómo el Arteterapia puede potenciar procesos antipsiquiátricos para conseguir una mejora en la calidad de vida de personas con enfermedad mental. Para dar respuesta a este planteamiento, se describe una experiencia arteterapéutica realizada durante 8 meses en la mini-residencia AFAP (Madrid, España) con personas con enfermedad mental. Se recoge lo ocurrido, las obras realizadas, las propuestas planteadas, entrevistas a diferentes profesionales del centro, a una arteterapeuta del taller y a varias personas con enfermedad mental que formaron parte de la experiencia. Se concluye que las necesidades de cambio existen y se hacen reales cuando se da voz a las personas con enfermedad mental. El Arteterapia es uno de los recursos que puede mejorar el sistema de salud mental.

\section{Palabras clave}

antipsiquiatría | arteterapia | enfermedad mental | cambio

Recibido

12 ago. 2017

Aceptado

31 nov. 2017

Publicado

22 dic. 2017

Editor

Nicolás Alessandroni | Facultad de Psicología, Universidad Autónoma de Madrid (España)
ISSN

2422-572X

Licencia

(c) Copyright: Gómez López, Y. Este trabajo se distribuye bajo una licencia de Cultura Libre CC-BY 4.0

\section{Entidad editora}

RevPsi es una publicación de la

Facultad de Psicología (Universidad

Nacional de La Plata, Argentina)

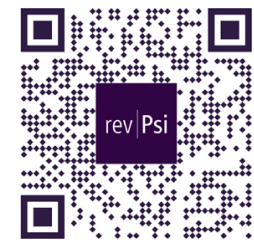

ACCESO ABIERTO DIAMANTE ə 


\section{Arteterapia e antipsiquiatria. Arteterapia como ferramenta de mudança}

\section{Resumo}

A arte gera espaços para crescimento, escuta, suporte, rede e organização que possibilitam mudanças. A antipsiquiatria, baseada nas necessidades e demandas atuais, propõe mudanças e melhorias no sistema de saúde mental. Esta pesquisa explora como Art Therapy pode melhorar os processos antipsiquiátricos para alcançar uma melhoria na qualidade de vida das pessoas com doença mental. Para responder a essa abordagem, descrevemos uma experiência de terapia de arte realizada durante 8 meses na mini-residência da AFAP (Madri, Espanha) com pessoas com doença mental. Inclui o que aconteceu, os trabalhos realizados, as propostas apresentadas, entrevistas com diferentes profissionais do centro, um arteterapeuta da oficina e várias pessoas com doenças mentais que fizeram parte da experiência. Conclui-se que as necessidades de mudança existem e se tornam reais quando se dá voz a pessoas com doenças mentais. Arteterapia é um dos recursos que podem melhorar o sistema de saúde mental.

\section{Palavras-chave}

antipsiquiatria | terapia artística | doença mental | mudança

\section{Art therapy and antipsychiatry. Art therapy as a tool for change}

\section{Abstract}

Art generates spaces for growth, listening, support, networking and organization that make changes possible. Antipsychiatry, based on current needs and demands, proposes changes and improvements in the mental health system. This research explores how Art Therapy can enhance antipsychiatric processes to achieve an improvement in the quality of life of people with mental illness. To respond to this approach, we describe an art therapy experience carried out during 8 months in the AFAP mini-residence (Madrid, Spain) with people with mental illness. It includes what happened, the works carried out, the proposals put forward, interviews with different professionals of the center, an art therapist from the workshop and several people with mental illness who were part of the experience. It is concluded that the needs for change exist and become real when giving voice to people with mental illness. Art therapy is one of the resources that can improve the mental health system.

\section{Keywords}

antipsychiatry | art therapy | mental illness | change 


\section{Aspectos destacados del trabajo}

- Se describe una experiencia de intervención arteterapéutica realizada en una mini-residencia en Madrid, España.

- Se presentan imágenes originales derivadas de la experiencia y fragmentos de entrevistas.

- Se explican los vínculos entre el Arteterapia y la antipsiquiatría

- Se concluye que el Arteterapia es uno de los recursos que puede mejorar el sistema de salud mental y se explicita por qué.

\section{La antipsiquiatría}

El término antipsiquiatría fue creado por David G. Cooper, analizado en su libro La gramática de la vida, en el que describe la experiencia llamada Villa 21, realizada en un hospital psiquiátrico de Londres. Fue una experiencia alternativa a la psiquiatría tradicional que sirvió como ensayo dónde los pacientes se encontraban sin restricciones, sin violencia ejercida por la institución y en un ambiente de libertad. La antipsiquiatría como movimiento científico se inició en Gran Bretaña, siendo, Ronald D. Laing, David Cooper y Aaron Esterson sus principales referentes desde los años 60 hasta inicios de los 80 del pasado siglo. El motivo principal fue la abolición de los manicomios, que no solo no sanaban a la persona ni aliviaban su dolor o sufrimiento sino que, potenciaban la sintomatología y cronificaban la enfermedad. Los grupos que surgieron en un principio fueron bastante reducidos, pero poco a poco fue ganando más fuerza, teniendo mucha repercusión en la psiquiatría tradicional.

En estos momentos la situación de la psiquiatría ha cambiado pero este movimiento no ha desaparecido sino que sigue en constante cambio y crecimiento, cada vez existen más espacios, dispositivos, recursos o profesionales que se nutren de su ideología. Actualmente la antipsiquiatría de un cuestionamiento de la psiquiatría actual, una actitud permanente de mejora de los derechos y la situación de las personas con enfermedad mental.

La antipsiquiatría plantea el cuestionamiento de diferentes temas. A continuación se profundiza los más relevantes para el presente trabajo.

\section{Las etiquetas}

En1961, Thomas Szasz fue iniciador de un debate que se extendió a nivel mundial cuestionando por qué se hablaba de enfermedad mental cuando la mente no es un órgano. Se planteó cómo los diagnósticos son etiquetas de conductas no comunes, útiles para patologizar a las personas diferentes, a la heterogeneidad, a lo que está 
fuera de la norma, y se habla de recuperación o de cura cuando estas personas cambian hacia un comportamiento aprobado por la sociedad.

David Cooper (1964) valida la enfermedad mental, la plantea como algo funcional asegurando que es la consecuencia inventada de un individuo libre en su totalidad para poder vivir una situación no vivible. En palabras de Basaglia, "los trastornos mentales, responden a una situación humana y esto es válido siempre; en un segundo momento, esta situación humana se cataloga, y es ahí donde aparecen las etiquetas de la enfermedad" (citado en Obiols, 1973, p. 80). Los trastornos mentales responden por tanto a una situación concreta, tienen una función en el individuo y muchas veces se manifiestan de forma transitoria. Según Juan Obiols:

La enajenación son situaciones a las que muchos pacientes no llegan jamás, y cuando su trastorno los conduce a situaciones en las cuales su capacidad de juicio o de interpretación de la realidad, se altera, se trata de estados casi siempre transitorios (Obiols, 1973, p.117.)

La antipsiquiatría pone de manifiesto que cuando se diagnostica a la persona poco a poco la etiqueta va ganando más peso y espacio en su identidad y demás áreas de sí mismo; un diagnóstico de enfermedad mental puede llegar incluso a anular a la persona, su voluntad e incluso su responsabilidad penal (Desviat, 2006). Hay que destacar además la connotación negativa de los trastornos mentales, las consecuencias del estigma.

\section{La medicación}

El primer recurso que ofrece la psiquiatría frente a la enfermedad mental es la medicación, actualmente hay millones de personas en el mundo que toman algún tipo de medicación psiquiátrica. Además los sistemas psiquiátricos son muchas veces carentes, no permiten que los psiquiatras o psicólogos puedan tener un acompañamiento adecuado a las personas:

Se me ofreció lo mínimo. Un psiquiatra que te ve cada mes o dos, veinte minutos y te pregunta si te has tomado tu medicación, un enfermero que te pregunta qué tal estás, qué tal tu familia... lo demás es arsenal químico (Rey, 2014, p. 13).

Las medicaciones psiquiátricas tienen su función y es necesaria en muchos momentos, pero hay que tener en cuenta que son tóxicas y pueden llegar a dañar el cuerpo, además de la gran cantidad de efectos secundarios que tienen. El autor de la guía de reducción del daño Will Hall expone:

Usé diferentes drogas psiquiátricas durante varios años, pero los profesionales médicos que las recetaron nunca me hicieron sentir empoderado o informado. No me explicaron cómo funcionaban, no discutieron conmigo honestamente sobre los riesgos, no me ofrecieron alternativas ni me ayudaron a dejarlas 
cuando no quise tomarlas más. La información que necesitaba no estaba, estaba incompleta o era incorrecta. Cuando finalmente empecé a aprender nuevas formas para estar mejor, no fue gracias al sistema de salud mental, sino a pesar de él (Hall, 2009, p. 5)

La antipsiquiatría en este caso se caracteriza por darle voz a la persona, situándola como dueña, responsable y partícipe de su propio tratamiento, exigiendo que haya un control en el uso de fármacos, que se contemplen otras opciones de tratamiento y, sobretodo, que se ofrezca la información necesaria. En todo esto debe existir un acompañamiento por parte del profesional que la ayuda a que tome sus propias decisiones ofreciéndole para ello una información que sea sincera, cuidándola en ese camino de aprendizaje que ella misma está marcando. Todo centrado y adaptado a la persona para que viva sus experiencias como desee, haciendo uso de su derecho a la autodeterminación. Como cualquier persona, debería tener la convicción de que la esencia de toda vida saludable es la capacidad de estar empoderado (Hall, 2009).

\section{Rol profesional-paciente}

Entre los precursores del movimiento antipsiquiátrico se encuentra la doctora Sechehaye con su obra Diario de una esquizofrénica, en el que explica el proceso terapéutico desde una postura distinta a la tradicional de médico- enfermo. Plantea el encuentro entre dos seres humanos que están teniendo una experiencia común. Los propulsores de la antipsiquiatría anteriormente nombrados, como Cooper con su experiencia en la Villa 21, Goffman y su interés por compartir los espacios habituales de las personas internadas, Basaglia con la comunidades terapéuticas en Italia, entre otros, también pusieron en cuestionamiento esos roles y las funciones que hasta entonces ellos mismos habían ocupado, observando además los cambios significativos y positivos que fueron descubriendo al colocarse en otro lugar al habitual para tratar al paciente.

El antipsiquiatra, por tanto, se desprende de lo seguro, del protocolo que dirige su actuación, encontrándose de forma presente en el espacio y apoyándose en sus recursos internos para actuar. En palabras de Nicolás Caparrós, doctor en medicina, psiquiatra y psicoanalista:

El psiquiatra, poseedor de unos conocimientos determinados, producto de un momento social específico y depositario social de la conservación de las normas definidas. El paciente "distinto" de algún modo, "señalado" de alguna manera, perturbador-perturbado. El entorno, testigo activo y modificante de la relación interpersonal citada. Para cada instante, un grado distinto de conciencia. Una reflexión final: los psiquiatras provienen siempre del bando de los sanos, los enfermos mentales nunca producen a su propio psiquiatra o, por lo menos, la sociedad nunca les otorga el título de tales. Por tanto, la antipsiquiatría cuestiona el rol del profesional de la salud que en ocasiones es desigualitario y de poder respecto a la persona con enfermedad mental. Olza dice: 
Me siento traumatizada por el maltrato y la violencia que he percibido y que a veces he ejercido yo misma en las urgencias psiquiátricas. Atendiendo malamente a montañas de pacientes con un alto sufrimiento al que desde lo público ya casi sólo se responde con más y más pastillas y/o contenciones mecánicas, eufemismo del clásico 'atar a la cama' (Olza, 2014, p. 3).

\section{La escucha y los vínculos}

Las redes sociales, los vínculos personales de las personas con enfermedad mental pueden verse afectados o desaparecidos por la propia enfermedad, por el estigma o por el ingreso en una institución. El aislamiento se da incluso entre las personas con enfermedad mental que conviven en un mismo espacio común.

La antipsiquiatría promueve más espacios que faciliten el vínculo entre iguales ya que en este tipo de espacios se promueve la dignidad y el empoderamiento entre las personas, enfatizando en el poder que tiene cada individuo en su propio proceso de sanación, en la compasión, la aceptación y el respeto hacia uno mismo.

\section{El aislamiento}

Jorge Fernández, artista, autodenominado loco y parte del Frente de artistas del Borda escribe:

La libertad de ser libre como los pájaros, y no ser encerrado en este claustro de sombras. Sombras policiales que se ven en este claustro de sombras. Sombras calavéricas de nuestros pasos por este hospicio. Hospicio de muerte ¡Destrocen los muros por favor! (citado en Sava, 2008, p. 36)

Muchos siglos atrás surcaba el barco de los locos alejando a aquellas personas que eran consideradas peligrosas, distintas, anormales, enfermas, locas, del resto de la sociedad. Ese barco fue sustituido por manicomios en su posterioridad. En palabras de Basaglia:

Peligroso para sí mismo y para la los demás; y de escándalo público (...) Si el enfermo, antes de ser considerado como tal, debe considerarse sobre todo peligroso, las reglas en las que se basa la institución que debería ocuparse de su curación, no pueden instituirse más que en función de esta peligrosidad y no de la enfermedad que padece (citado en Sava, 2008, p. 20)

La antipsiquiatría se centra en de dinámicas más comunitarias y sociales para romper ese aislamiento social, se propone por tanto un cambio en el imaginario social, para que las sociedades se conviertan en espacios más inclusivos donde se compartan derechos y responsabilidades.

La antipsiquiatría enfatiza en la necesidad de que la asistencia a la persona ocurra, 
mientras que sea posible, en su ambiente habitual, sin que abandone a su familia, amigos, trabajos y rutinas porque este tipo de experiencias han demostrado ser más eficientes que aquellas intervenciones que implican un ingreso.

Agrega un padecimiento adicional al que ya sufren las personas que ingresan en la institución. La fragmentación de los lazos sociales, junto al temor permanente, conlleva la resignación y el desinterés frente a una situación que se percibe como sin salida; lo que suele dar paso al aislamiento y a la paulatina desaparición de la conciencia crítica (Sava, 2008).

Concluyendo en palabras de Patricia Rey:

Tengo la intuición de que en una sociedad en que cuando delirases, no te ataran, no te pincharan, no negaran lo que estás viviendo como algo terrible y enfermo, no te añadieran sufrimiento, te acompañaran... por supuesto que seguramente lo viviríamos de otra forma, mucho menos traumática, con mucho menos dolor (Rey, 2014, p. 11).

\section{El arte en los procesos antipsiquiátricos}

"El arte en los manicomios es casi tan viejo como los propios manicomios" (Sava, 2008, p. 23). Alberto Sava (2008) detalla cuál es el papel que tienen las producciones artísticas realizadas en las instituciones psiquiátricas en los procesos actuales de antipsiquiatría, donde la obra debe atravesar los muros físicos y también los simbólicos. De esta forma este tipo de arte actúa en tres niveles: institucional, social y subjetivo.

A nivel institucional porque se pone de manifiesto la realidad y las condiciones de vida de las personas con enfermedad mental ya que en las producciones artísticas aparece la situación que se está viviendo. El sufrimiento causado por lo que conlleva la internalización y el aislamiento en la institución mental, la falta de libertad, la medicación, la posible violencia, abusos o vulneración de sus derechos se hace presentes en espacios que permiten debates y mejoras de las problemáticas existentes. Y lo que circula no es sólo la producción sino el artista.

A nivel social, porque la finalidad de que las obras salgan de los muros es acercar a las personas con enfermedad mental a la sociedad para que ésta vaya tomando conciencia sobre la verdadera realidad de la enfermedad y por tanto vaya perdiendo fuerza el estigma. El arte puede crear un vínculo con la comunidad y romper con el imaginario social de la locura que normalmente es negativo, puede convertir a la sociedad en un espacio de contención frente a las posibles crisis de un individuo, disminuyendo por tanto su sufrimiento e incluso la propia enfermedad. Además la persona con enfermedad mental puede presentarse de nuevo frente a la sociedad siendo un individuo productivo, que crea y construye a través de sus obras.

A nivel subjetivo, porque el arte puede devolver a la persona todo aquello que la 
institución o la enfermedad le quitan, como sus deseos, sus pasiones, sus sueños, su proyecto de vida, su capacidad creativa y su capacidad de estar en el mundo. El proceso creador permite recuperar estas cosas y conecta al individuo consigo mismo, lo empodera, lo trasforma y le devuelve la responsabilidad y la posibilidad de cambio. Además, el arte convoca también a un trabajo grupal dentro del proceso creador, a sentirse parte de un colectivo o de un grupo de personas con un interés o situación común potenciando un diálogo y una escucha distinta, que potencia los vínculos personales y por tanto de tejido social. La actividad artística produce todo tipo de movimientos personales y grupales de los que la persona se beneficia. El arte compromete con la vida:

Los manicomios son ciudades levantadas a base de hipocresía y represión; intentan ocultar lo que ellas mismas producen, el malestar, la euforia, la desesperación. El lugar elegido es un hospital de encierro y el tratamiento consiste en algunas charlas y miles de pastillas; contra ese dispositivo nos levantamos, cantamos, escribimos, actuamos, contamos,... nuestras producciones artísticas intentan hacer circular las voces y los pensamientos apresados, las historias apresadas, las luchas encarnadas (...) (Sava, 2008, p. 36)

\section{Objetivos de la investigación}

El objetivo general de esta investigación es explorar cómo el Arteterapia puede potenciar los procesos antipsiquiátricos. Para llevar a cabo ese análisis se plantean una serie de objetivos específicos:

- Conocer cuáles son las necesidades de cambio y de mejora de las personas con enfermedad mental.

- Identificar qué cambios se han producido y qué ha aportado el taller de Arteterapia a las personas con enfermedad mental que han participado

- Conocer la opinión que tienen algunas personas con enfermedad mental de su situación y de la experiencia arteterapéutica vivida.

- Conocer la opinión de los profesionales que trabajan en la institución mental sobre el Arteterapia y sobre la situación actual de la psiquiatría.

- Describir las convergencias entre los puntos de vista explorados y su relación con los ejes principales que propone la antipsiquiatría.

\section{Metodología de la investigación}

Para abordar el tema de estudio, se propone una investigación de corte cualitativo y de paradigma fenomenológico por la reflexión sobre los procesos humanos y sociales. 
En esta investigación se lleva a cabo una triangulación metodológica, explicada por Arias (2000) como la combinación de dos o más tipos de recolección de datos. Uno de los métodos ha sido la observación participante. El diario de campo ha permitido recoger todo lo ocurrido en cada sesión así como el traspaso de información de distintos profesionales del centro. Existe también un registro de las opiniones de cada participante sobre lo sucedido en el taller, así como entrevistas semiestructuradas a cuatro participantes del taller, a una de las arteterapeutas facilitadoras del espacio y a la psicóloga de la mini-residencia. Las obras artísticas de los participantes también han aportado información.

\section{Contextualización del ámbito de estudio}

La información analizada en este estudio parte de lo observado a partir de la intervención arteterapéutica de 8 meses (Octubre-Mayo) en la Mini-residencia AFAP: servicio residencial, comunitario supervisado, abierto, flexible y de carácter voluntario para personas con enfermedad mental grave y duradera estabilizada. La Mini-residencia se encuentra en el municipio de Pedrezuela, en la zona norte de la Comunidad de Madrid, España. El taller ha tenido una duración de 1:30h a la semana realizado en dos turnos: turno de mañana y turno de tarde. Son dos profesionales de la Arteterapia las que facilitan el espacio arteterapéutico.

Los participantes del taller de Arteterapia son personas que viven en la residencia aunque su estancia puede variar, desde una estadía puntual de un tiempo concreto o de forma permanente. Dichas personas han sido diagnosticadas en algún momento de su vida de algún trastorno mental, son enfermos crónicos y en algunos de ellos el deterioro cognitivo está muy presente.

\section{Desarrollo del contenido y resultados}

A continuación se presentan los resultados de cómo el arte y el taller de Arteterapia en la mini-residencia han podido potenciar, a nivel subjetivo, los cambios propuestos en los cinco ejes principales de la antipsiquiatría planteados anteriormente.

\section{De las etiquetas al reencuentro con el ser auténtico}

Varias opiniones de participantes del taller y profesionales de la mini-residencia, apoyan los cuestionamientos antipsiquiátricos sustentados en el marco teórico.

Retomando a Thomas Szasz y el debate que cuestiona por qué se habla de enfermedad mental, JA participante del taller de Arteterapia tiene el mismo planteamiento a partir de su experiencia:

Cuando yo he tenido problemas psíquicos yo no he podido entender cómo se podía saber cómo sabían que una persona está enferma, porque eso está ahí dentro de la cabezota o lo que sea, tú tienes un grano entonces yo lo veo pero en esto que me pasa no. 
Las palabras de la psicóloga de la mini-residencia, añaden además las ideas antipsiquiátricas de no entender al individuo como enfermo sino a considerar dicha enfermedad como resultado de lo que ocurre en un sistema familiar y social:

Sería necesario considerar la enfermedad mental (sin olvidar que no es una enfermedad según la OMS) como un problema sistémico, familiar, y no sólo como un diagnóstico que atribuimos a un miembro de la familia, exonerando al resto de familiares de responsabilidad y patología e incluso permitiéndoles entronarse como personas válidas para dirigir la vida del supuesto enfermo.

En palabras de CA, participante del taller:

Es que yo no sé qué tengo en la cabeza. Yo estuve en el hospital el 11, el 12, el 13, un doctor me dijo que yo tenía Esquizofrenia residual, Trastorno orgánico de la personalidad y minusvalía del 70\%, se acabó, y ¿cómo se come eso? Pues no tengo ni idea porque yo vivo aquí como si no tuviera nada, nada de nada. Es como si te precintaran una marca, eres esto y esto, y tú respondes de una manera u otra. (...) Me siento como inferior a los demás por esa etiqueta.

Las palabras de JA confirman lo planteado en el marco teórico sobre cómo el diagnóstico es práctico para el profesional pero pocas veces es confuso para el que lo padece:

Mi diagnóstico es esquizofrenia residual y no sé, no entiendo bien qué significa.

Respecto a la enajenación o a las crisis que pueden ser entendidas como momentos concretos y puntuales, funcionales en muchos momentos como Juan Obiols, Franco Basaglia o David Cooper exponían, TA, la psicóloga de la mini-residencia afirma que:

Creo que sería nuclear acabar con el miedo y con la idea de 'para siempre' que conllevan los diagnósticos y que los psiquiatras te ofrecen al recibir el diagnóstico.

Frente a esto el Arteterapia se sitúa en esta línea de intervención donde la persona es recibida no según el colectivo del que forma parte o por una de las características que lo determinan, sino que se tiene en cuenta su ser completo, desde lo que es en ese momento concreto y de lo que quiere traer a ese espacio en el aquí y ahora. La enfermedad no es el eje central del espacio terapéutico y esto permite que la persona se concentre en otras cosas dejando de lado aquello que ocupa la mayor parte de su atención. Opiniones de los participantes al taller como la de JO refuerzan esto:

Estar con la mente en blanco y no pensar en las cosas que nos pueden hacer daño o estar preocupados, quitarnos las preocupaciones y el sentirse mal. 
O como la de IN:

Me ha aportado momentos de paz de alegría, con el problema de la incapacitación, con el alta. Olvidarme un poquito de que estoy enferma, de que puedo ser normal, como los demás y que puedo aportar algo aunque sea un intento de realizar un rostro.

Estos testimonios onfirman que para los participantes el Arteterapia no es un espacio en el que se tenga una intención de tratar la enfermedad mental sino que se permite que ocurran otras cosas. En conclusión:

El arte por su carácter universal permite que, si cargas con un diagnóstico psiquiátrico, "olvides" por un momento el lastre de la enfermedad y lo que conlleva y crees desde lo subjetivo (TA, psicóloga).

En ocasiones la institución mental tiene que responder por todos los residentes y esto puedo que no sean atendidas y reconocidas las necesidades de las personas que la habitan como los sueños, los deseos, los gustos o aquello que tiene que ver con la esencia de la persona o su desarrollo personal. Se recupera en el espacio arteterapéutico la capacidad de soñar, de manifestar los deseos de uno, las necesidades, aquello que gusta y lo que no, lo que emociona o hace temer, la alegría el miedo, los recuerdos, etc., mediante una forma de expresión distinta. Como dice UL, participante del taller:

El arte para mí es tener algo para desenvolverte, para deshacerte de ese lio, dejar de darle vueltas a las cosas, ponerlas en su sitio. (...) El arte para mí significa tener desenvoltura, tener costumbres, tener manías, tener todo eso, eso es arte. Todo el mundo tiene algo que decir.

A continuación se presentan varias obras de diferentes autores. Se puede observar cómo el espacio arteterapéutico recoge todo lo que tenga que ver con lo propio del individuo.

Volviendo a la institución hay que remarcar que, en muchos casos conlleva unas rutinas necesarias pero poco estimulantes, eso sumado a la abulia o apatía consecuencia de la enfermedad o de la medicación hacen que las personas pasen gran parte de su tiempo sin hacer nada o haciendo las mismas cosas. En palabras de los participantes del taller:

Llevo mucho tiempo ya llevo 3 años, el primer año lo pasé muy mal, era muy agobiante, no está acostumbrado al tiempo, a la rutina del día a día (C.F.).

Nos aburrimos mucho, tenemos muchos problemas y eso que no se ve pero se siente, no se ve pero se siente (UL). 
Frente a esto, el Arteterapia permite generar experiencias diferentes que permitan a los participantes encontrarse en lugares distintos, que salgan de la rutina, del aburrimiento y de la tendencia a la repetición que caracteriza a las personas con enfermedad mental. El taller da la posibilidad de hacer cosas nuevas y permite a la persona colocarse en otro lugar y explorar qué sucede desde ahí: "Un poco de hacer algo nuevo, es una actividad bonita que me gusta."(DI) "Experimentar con materiales que yo desconozco (IN), "Hacer cosas diferentes y tener más cultura" (AN), "Estar entretenida y distraída con algo diferente" (IS). Con este planteamiento de no hacer siempre lo mismo, el Arteterapia también se puede convertir en un espacio de ocio y diversión que puede mejorar la calidad de vida de la persona, tanto los participantes valoran este recurso por su entrenamiento:

¿El taller? A mí me divierte muchísimo, no puedo decir más (PA).

Además facilita una opción de ocio, algo con sumo interés si te encuentras institucionalizado o has perdido tus relaciones sociales y aficiones (TA, psicóloga).

Pero además, la importancia de generar nuevas experiencias es lo que queda en la persona después de la vivencia, el Arteterapia permite conectar con capacidades olvidadas o nunca descubiertas y desviar la atención de las carencias a las posibilidades. Los participantes han reflexionado sobre ello exponiendo que:

$\mathrm{El}$ arte es tener valor para hacer una cosa. Arte es valor de reconocerse a sí mismo, de reconocer las cosas (UL).

El arte es superarme y desarrollarme como persona, como todo, yo pintando, trabajando y creando me siento muy bien" (CA).

El arte puede suplir la carencia como Toulouse que por ejemplo no podía caminar bien, a través del movimiento de la bailarina, ejercitaba el movimiento de una forma plástica. Puede rellenar huecos y ayudar mucho en general porque además no perjudica en nada, es siempre positivo (PA).

El orgullo de decir he hecho una cosa pequeñita pero es algo mío, ha salido de mis manos, soy creador y puedo considerarlo como un pequeño acto de Dios, soy como una pequeña colaboradora de la maravilla que es el mundo (IN). 


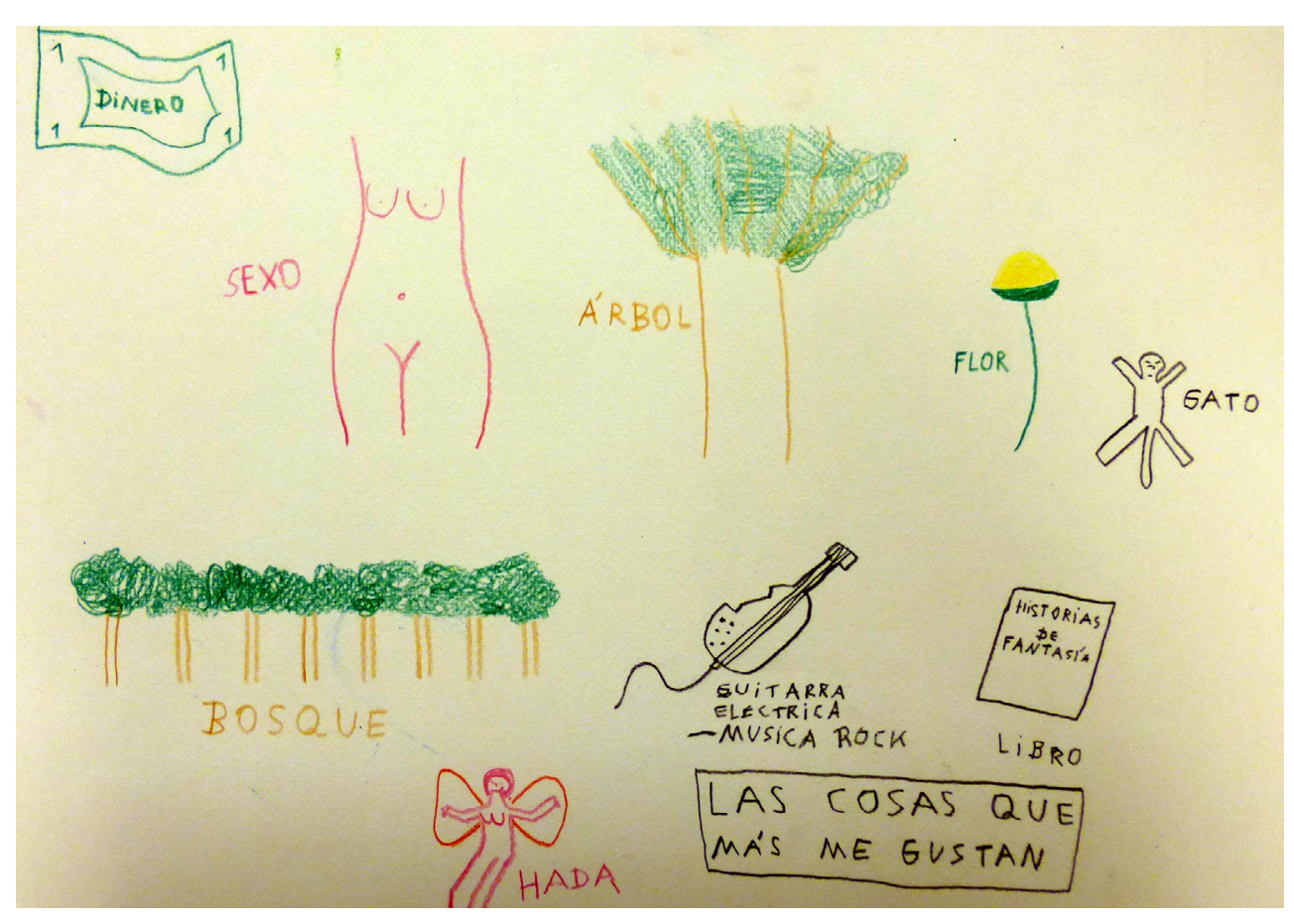

Figura 1. Obra "las cosas que me gustan" por DI. El participante muestra sus gustos y lo comparte con sus compañeros que aunque se conocen desde hace tiempo porque comparten diariamente los mismos espacios se muestran sorprendidos al descubrir cosas nuevas de él.

Y en palabras de la psicóloga:

Te permite sentirte libre y válido, pese a que el entorno psiquiatrizador se empeñe en hacerte sentir minusválido o cuanto menos, raro, a parte, excluido. Desde esta perspectiva, contribuye a mejorar la auto- estima que la enfermedad mental te haya podido robar.

El Arteterapia por tanto da la posibilidad de que la persona vaya más allá de los límites de su enfermedad y conecte con su ser auténtico. 


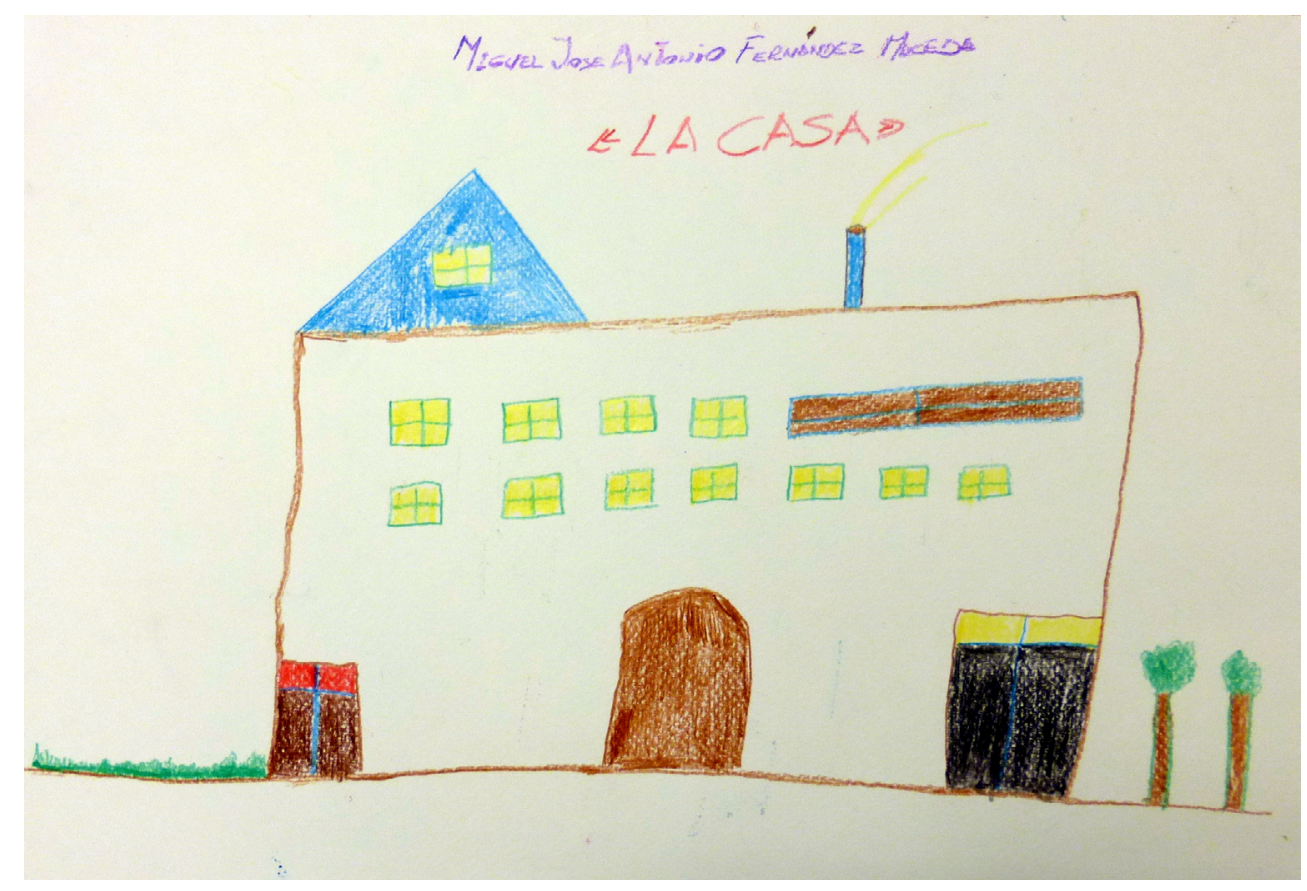

Figura 2. "La casa" por MI. MI realiza la casa en la que le gustaría vivir en un futuro, una casa grande en la que poder convivir felizmente con familia y amigos. MI expresa que este es un gran deseo que tiene desde hace años.

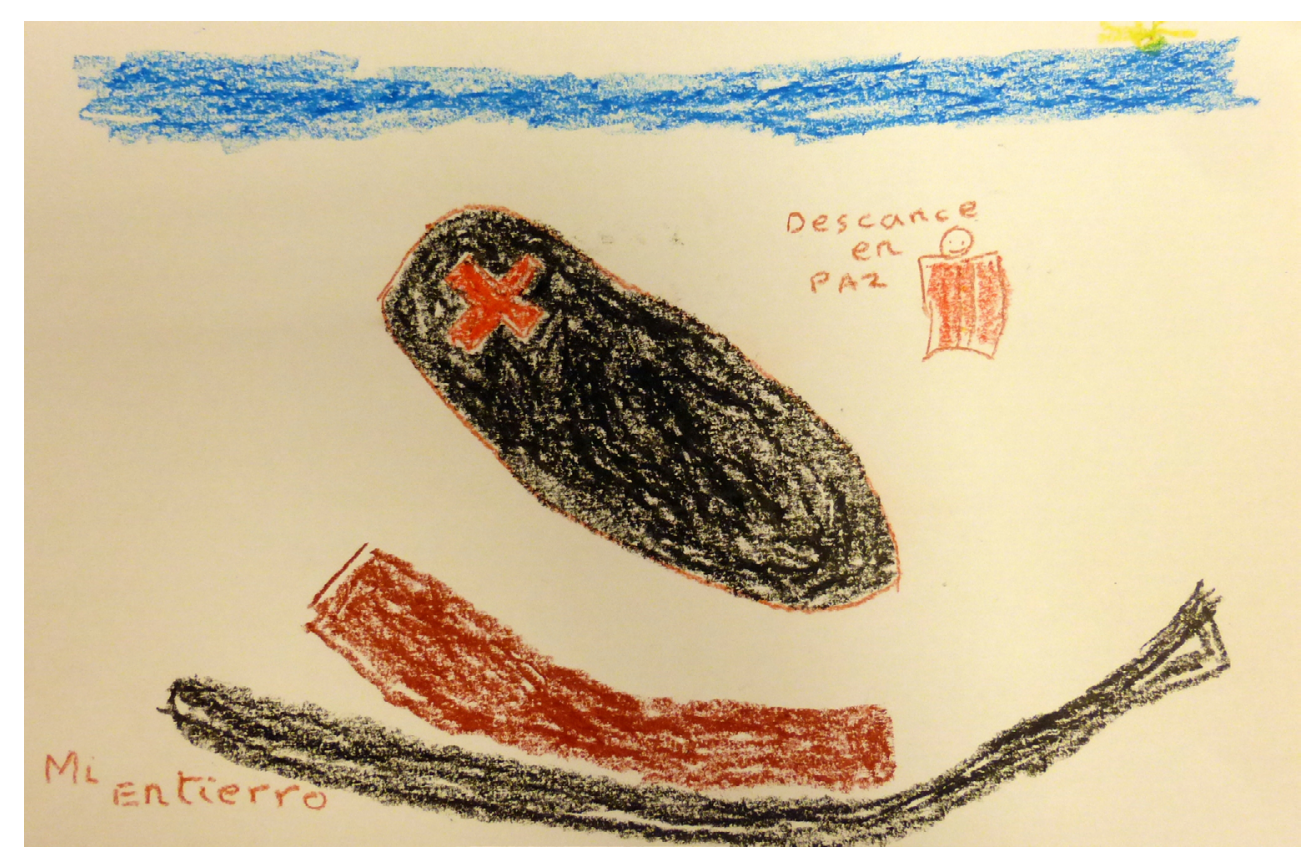

Figura 3. "Mi entierro" por RI. En esta obra RI, de 70 años de edad expresa su miedo a la muerte, muy presente en esos días para él a partir de la representación de su propio entierro. 


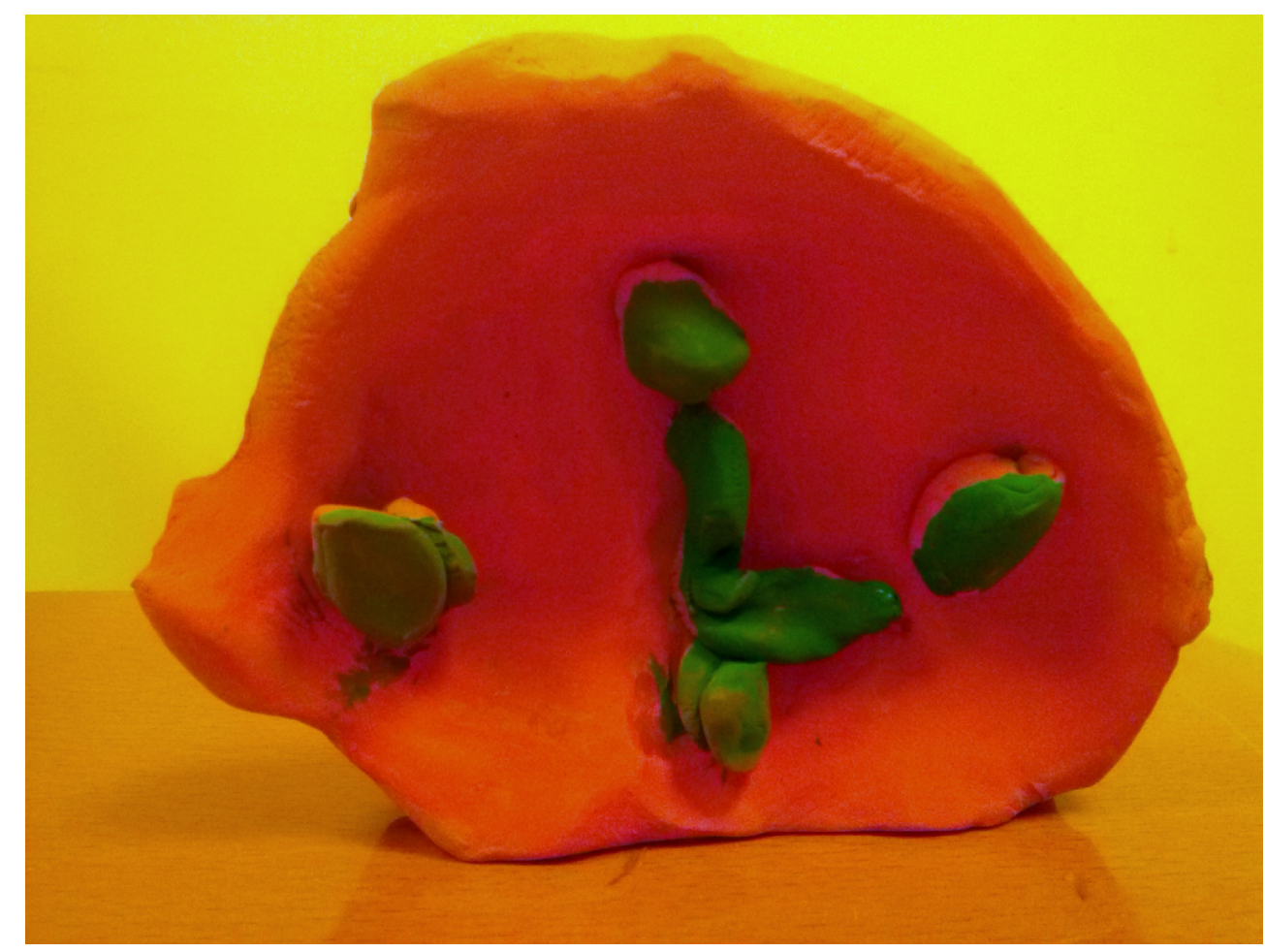

Figura 4. "En el reloj no avanzan las horas" por M.AN. En la presentación de esta obra se hace alusión a que este reloj es como el reloj de la vida, donde no avanzan las horas.

\section{De la medicación a la responsabilidad personal}

La psiquiatría en estos momentos opta por la medicación como primer recurso en el tratamiento de personas con enfermedad mental. Los fármacos son útiles y necesarios pero en ocasiones su forma de utilización a veces excesiva, desinformada y desamparada. Por ejemplo C.F, participante del taller expresa respecto a la medicación:

Es un poco duro porque la medicación es muy fuerte, yo me tomo dieciocho pastillas al día y te deja cao. Hay días que estás por la calle, te sientas un rato y te vas, o estás caminando y te pesa, las piernas te tiemblan y no puedes caminar más, porque estás sedado, (...) lo que me gustaría cambiar principalmente es sacarme, quitarme la medicación que tengo (C.F).

Retomando el planteamiento antipsiquiátrico con autores como Will Hall se cuestiona el papel de la medicación, no como una oposición a ésta, sino que se reivindica la necesidad de dar la información necesaria y que se devuelva el poder de decidir a la persona y que sea ésta, acompañada y cuidada por un profesional la que decida cómo quiere que sea su proceso de curación y de mejora. En palabras de TA, psicóloga: 
(...) tengan siempre presente la libertad de la persona y confíen en sus capacidades en lugar de centrarse en los déficits o en lo que no es objetivamente 'normal' y que se dirijan y orienten a tratamientos con posibilidad de cambio (no sólo del paciente, sino también del profesional y cómo adaptarse a cada caso, sin esperar que sea el paciente el que se adapte a ellos) y que la tendencia de los tratamientos farmacológicos sea la reducción, al contrario de la práctica habitual de sobremedicación que especialmente sufren las personas a las que consideran crónicas.

La antipsiquiatría por tanto cuestiona el poder que tienen los profesionales de la salud que actúan y toman decisiones, sin hacer partícipe a la persona con enfermedad mental y no solo respecto a la mediación sino a otras cuestiones de su vida:

-¿Los cambios no los eliges tú? [autora] / -No, nunca. Los eligen los que van de jefes, los que se autoproclaman jefes de mi vida, o jefas (extracto de la entrevista de JA).

Frente a este tipo de situaciones la antipsiquiatría pretende por tanto devolver el poder personal y la responsabilidad a las personas con enfermedad mental, en palabras de TA (psicóloga):

Aumentar el respeto a la libertad e individualidad del diagnosticado, eliminando por completo comportamientos paternalistas de los profesionales, especialmente aquellos que conducen al profesional a 'manejar' la vida y el futuro del psiquiatrizado bajo la premisa 'yo sé lo que te conviene, no tú, sin su consentimiento ni aprobación y a veces, sin una mísera explicación.

Pero para que la persona pueda ser responsable de su proceso de enfermedad y tratamiento debe conectar con su capacidad de decisión, de asertividad, de su fortaleza personal y de percepción de empoderamiento y es desde ahí desde donde tiene sentido el Arteterapia.

En el espacio arteterapéutico se potencia la elección propia ya sea en la selección de los materiales que se quieren utilizar, así como las decisiones que conlleva el propio proceso creador que sitúa al individuo como agente de acción y de cambio. En palabras de MA, arteterapeuta también del taller:

Sí que veo la sensación de logro, de ser capaz de hacer cosas que, se les quita la capacidad de decisión ante nada, la responsabilidad y sí que la siguen teniendo, cada uno de una forma y el Arteterapia facilita eso (...). Claramente lo ha dicho CA varias veces, el fortalecer sus capacidades que de otras formas se les niega.

Además de lo comentado anteriormente sobre lo que el Arteterapia aporta en el proceso de conectar de nuevo con el empoderamiento y la responsabilidad personal, 
es interesante considerar el Arteterapia en sí misma como forma de tratamiento en la curación de cualquier persona:

El Arteterapia es a través del arte la curación o el tratamiento (JA)

Me ha parecido muy bueno como terapia (PA)

\section{Del rol profesional-paciente a la experiencia compartida}

Te voy a decir una cosa de eso del estigma, cuanto más estigmatizado me he sentido ha sido con profesionales de la salud mental. Son totalmente... hasta aquí (hace el gesto de colocar una barrera frente a él), creas confianza, creas entusiasmo y luego “ipumba!", habría que saltárselo y romper con el límite profesional, eso es un rollo, yo me he sentido peor con eso que con otras personas, la familia, los amigos, las personas se pueden reír pero lo peor es el 'hasta aquí.

Con estas palabras de JA, participante del taller, se retoma la idea antipsiquiátrica de romper con el rol desigual entre persona y profesional. El espacio arteterapéutico es un espacio totalmente flexible y centrado en la persona o grupo, donde el rol del arteterapeuta es relajado y permite un encuentro con el Otro real y sincero que nos da la posibilidad de comunicarnos ya sea mediante el lenguaje verbal o artístico.

El proceso creador y la obra actúan como mediadores de la comunicación y el vínculo entre el arteterapeuta y la persona, permitiendo que se reduzcan las defensas de la persona al no tener necesariamente que hablar de sí mismo. Es importante remarcar que el Arteterapia es un encuentro donde hay comunicación y para que se de dicha comunicación tiene que existir una escucha, una escucha activa. En palabras de Longui (2014), escuchar es más que oír con el oído, es una escucha con el cuerpo, con el alma, con el corazón. Una escucha desde el silencio. La escucha es un encuentro que produce comunión, unidad y por lo tanto un nosotros. En palabras de MA, arteterapeuta del taller,

No es que observes desde el exterior los cambios de una persona sino que tú estás dentro de esos cambios, estas formando parte de ellos y tú también estás cambiando.

Los profesionales de Arteterapia ofrecen vínculos distintos a las personas del resto de profesionales de la institución fuera de las dinámicas del día a día, pudiendo así responder a la otro tipo de necesidades presentes de la persona. MA, arteterapeuta

Más allá de facilitar experiencias nuevas pues somos unas personas nuevas en su vida y damos un espacio nuevo. 


\section{ÉPROHISIDO}

\section{PROHIBIR?}

\section{CPROHIBIR}

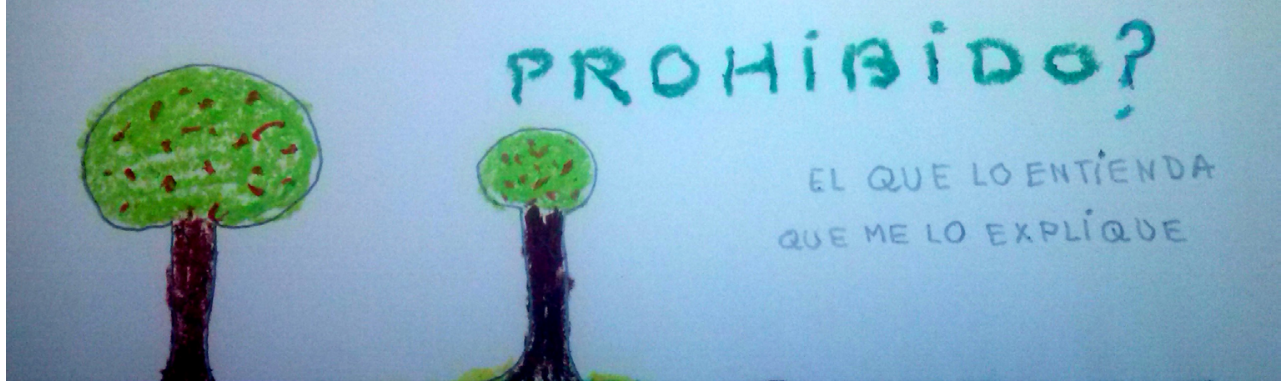

Figura 5. "Prohibido prohibir" por RI. RI expresa los conflictos que tiene con los profesionales del centro que, cumpliendo con sus funciones, le obligan a cumplir normas. RI siente frustración y enfado constantemente manifestándolo durante el taller, en el que se siente cómodo y en confianza.

\section{De la escucha y los vínculos al tejido social}

Frente al aislamiento que provoca la enfermedad mental y en muchos casos la institucionalización, la antipsiquiatría rescata la necesidad de que la persona tenga redes de apoyo, vínculos personales y familiares y un tejido social que la sostenga para disminuir así su sufrimiento y mejorar su calidad de vida.

Se lleva una vida un poco solitaria a pesar de que haya gente cerca (JA).

Mi hermano es importantísimo, si no fuera por él no sé dónde estaría. Hay un hombre aquí que se llama como yo, y ese tío está solo, no viene a verle nadie, completamente solo, es una putada, sobre todo para él (CA).

Cuando una persona está residiendo en una institución en ocasiones no tiene relación con las personas con las que conviven en el mismo lugar y se encuentran constantemente en los espacios comunes. La antipsiquiatría promueve espacios de escucha que faciliten el vínculo entre iguales y esto se consigue en un espacio arteterapéutico. Para algunos participantes del taller esto ha sido lo más significativo de la experiencia, en sus palabras: 
Una experiencia sobrehumana en la cual todos los compañeros nos hemos juntado y hemos hecho obras que yo creo que perdurarán durante muchos años. (...) Para pasar un rato agradable y estar en contacto, oír música a la vez que se dibuja y conocer a los demás miembros (RI).

El taller de Arteterapia es un espacio donde los participantes se encuentran y se relacionan a partir de los materiales artísticos, del proceso creador o de las obras. TA (psicóloga) valora estos meses de taller de la siguiente forma:

Ha aportado un espacio de libertad y no enjuiciamiento; un punto de encuentro entre los usuarios en el que no ha habido diferencias de capacidad sino nexos de comunicación. Ha contribuido a la mejora del autoconcepto y a la sensación de valía personal. Ha propiciado que se expongan ante los compañeros y en algunos casos, a romper rígidas estructuras mentales, fomentando la capacidad de adaptación. Creo que ha sido una oportunidad de sentirse distintos al rol de un enfermo.

El Arteterapia, por tanto, facilita que personas que forman parte del dispositivo grupal se escuchen de una forma distinta, que creen vínculos y una conciencia grupal que permite crear un tejido social.

Existe una necesidad por parte del ser humano de sentirse valorado, escuchado, comprendido y aceptado dentro del grupo al que pertenece, la acción artística permite las dos, permite expresarse dentro de la subjetividad de la persona y compartirla con un grupo,

“... Y también analizar, felicitar y aplaudir a los demás compañeros y darme cuenta que dentro de cada uno de ellos y de ellas hay un gran artista (IN, participante).

El medio artístico por tanto facilita además las interacciones entre los participantes ya que convierte lo que puede ser algo complejo en su estado natural en algo fluido dentro de una actividad.

El Arteterapia da la posibilidad de que las personas pueden hablar, ya sea a través del lenguaje verbal o del artístico, sobre su enfermedad, sin vergüenza y sin resistencias, sin miedo a no ser comprendidos o a ser juzgados. Algunos de los participantes han encontrado en el taller ese espacio para compartir aquellas cosas que no se animan a hacer normalmente, JA y UL por ejemplo, dicen:

Hay momentos en los que, por circunstancias una forma de expresión que está reprimida por uno mismo o por los demás, entonces como la expresión es inevitable porque te aprieta, te ahoga, se manifiesta con otra forma de lenguaje (JA). 
Yo tengo muchos altibajos pero veo que la gente también los tiene y me relajo, me vengo abajo y soy uno más entre ellos, (...) Me he dado cuenta de lo bueno que es hablar de estas cosas que me pasan no solo con los médicos (UL).

\section{Del aislamiento hacia la libertad comunitaria}

La antipsiquiatría surgió a partir de la violencia manicomial que existía hace décadas, del aislamiento de las personas con enfermedad mental recluidas entre los muros del hospicio. JA, un participante comparte con nosotras su experiencia de aquella época :

Es que hablando ya de tiempo atrás, yo empecé a estar enfermo cuando todavía no había dado un salto la sanidad que fue el de abrir los hospitales psiquiátricos e intentar que el adulto se tratase de forma ambulatoria y que estuvieras en casa, antes era como cárceles entrabas y no salías, no te podías quejar, sin duchar, sin asear...

Después esos muros se derribaron prohibiéndose en muchos lugares la figura de los manicomios pero aunque ha mejorado existen muchas personas que se sienten atrapadas en su situación:

Lo viven como que están aquí por obligación, una obligación que parte de la enfermedad, la enfermedad les obliga y también la sociedad (MA, arteterapeuta).

Ojalá no hubiera sido necesario hablar de ella, de la enfermedad y hubiera podido pasar mi vida trabajando, en la gasolinera por ejemplo y ser una persona como es toda la demás gente (UL, participante).

Estas palabras manifiestan la necesidad de que la persona con enfermedad mental tenga una vida lo más normalizada posible, con asistencia ambulatoria que permita ser atendida en su contexto personal y mantener su día a día, TA, psicóloga plantea para eso:

Evitar los ingresos psiquiátricos por todos los medios y si no es posible evitarlo, humanizarlos haciéndolos lo más breves posible, erradicando algunas situaciones lamentables que las personas con una crisis son sometidas a pasar en uno de los peores momentos de su vida como es una crisis psicótica; no despojar a quien vive un ingreso de toda posibilidad de contactar con el exterior, no hacerles sentir como presos.

Al preguntarles a algunos de los participantes qué quieren que pase con su vida, CA contesta que desea independizarse y vivir su vida, y C.F añade: 
Mi sueño es de quitarme toda medicación ponerme bien y poder irme a vivir a Portugal (...) Sí, porque aquí estoy solo, toda mi familia está en Portugal, entonces mi plan es comprarme una casita pequeñita de 40 mil o 50 mil euros e irme allá a vivir por eso estoy ahorrando, llevo cuatro cinco años ahorrando lo que puedo, ese es mi plan y mi sueño.

Por tanto existen personas con enfermedad mental con necesidad de cambio, de mejoras en su situación y esto implica una modificación del sistema mental para que existan los recursos y sean accesibles para que esto se pueda llevar a cabo.

El objetivo de esta experiencia arteterapéutica no fue que las obras de los individuos se visualicen fuera del espacio terapéutico, para lograr una repercusión social o institucional, como indicaba Sava. Para conseguir promover la libertad comunitaria a través del Arteterapia tendrían que exponerse las producciones, llevando las obras y la voz de las personas con enfermedad mental fuera de "sus muros", para incluir en este proceso de cambio al resto de la sociedad.

\section{Conclusiones}

Cuando se le da voz a las personas con enfermedad mental y a los profesionales que trabajan en los espacios psiquiátricos se puede ver una realidad en ocasiones compleja y caracterizada por el sufrimiento. A través de las palabras recogidas en este trabajo se comprueba que existen necesidades de cambio y de mejora en el sistema psiquiátrico y en los cuidados de la sociedad.

Como resultado se puede concluir que el Arteterapia potencia los procesos antipsiquiátricos ya que se aproxima al participante, como reclama la antipsiquiatría, sin etiquetas, sin estigmas, reconociendo al ser completo permitiendo que esa característica tan limitante en su vida pierda fuerza. La persona es percibida por el arteterapeuta sin exigencias, sin pretensiones, asumiendo tan solo lo que hay, lo que es y no lo que debería ser. Las nuevas experiencias permiten recuperar aquello que en ocasiones desaparece a consecuencia de la institucionalización, por una parte estímulos externos que ocupen tu tiempo y momentos de ocio también frente a las rutinas tan marcadas que existen. Cuando esta persona se permite experimentar, participar, hacer, crear,... se encuentra en un lugar distinto y puede conectar con diferentes potencialidades, capacidades nunca descubiertas e incluso limitaciones. Lo más frecuente según las valoraciones de los participantes es conectar con la capacidad de logro, de empoderamiento, de libertad, de mejora de la autoestima, es decir de sentirse válido cuando el proceso psiquiatrizador tiene tendencia a ejercer sobre la persona el efecto inverso.

Por otro lado el cuestionamiento de la medicación es otro de los pilares más relevantes de la antipsiquiatría, donde se propone que la persona con enfermedad mental recupere el poder de decisión sobre su tratamiento, acompañado e informado por un profesional que respete sus procesos. El Arteterapia puede potenciar las capacidades 
necesarias para que la persona se sumerja en un proceso en el que conecte con su responsabilidad personal, fomentado la toma de decisiones a partir de la elección en los materiales, así como las decisiones que conlleva el propio proceso creador que sitúa al individuo como agente de acción y de cambio.

El Arteterapia además se ajusta a la línea de planteamiento de la antipsiquiatría por la presencia de un profesional que rompe con el rol de profesional-paciente tan marcado en la psiquiatría. La figura del arteterapeuta en esta experiencia al igual que el antipsiquiatra se aleja de protocolos de actuación a veces limitantes, se aleja de lo seguro, de lo que debería ser para centrarse en lo que es, para potenciar un encuentro auténtico y a construir a partir de ahí con la persona o con el grupo. Además de eso, el arteterapeuta asume el papel que tiene la persona con enfermedad en las cosas propias que se movilizan en él. Los profesionales del Arteterapia ofrecen vínculos nuevos y distintos frente al contacto tan periódico que tienen con otras figuras, como son los educadores, psicólogos, terapeutas, etc.

La necesidad de que la persona con enfermedad mental tenga un tejido social que lo cuide y contenga, es importante y prioritario en la antipsiquiatría. El Arteterapia promueve que se establezcan vínculos y relaciones entre las personas del propio grupo, ya que, aunque puede que compartan otros espacios, en el espacio arteterapéutico pueden encontrarse de forma distinta, comunicándose además a partir de los materiales, del proceso creador y de la obra. Además de esto, la persona con enfermedad mental comprueba que puede compartir aquello que necesita expresar sobre su enfermedad y romper con la vergüenza o las barreras que se tienen normalmente con este tema, producto de un valor social extendido. Expresar a partir de la obra realizada facilita que se hable de uno mismo por no sentirse tan expuesto al grupo. En el espacio arteterapéutico por tanto las personas con enfermedad mental comprueban que no solamente pueden recibir una escucha y unos cuidados por parte del médico, psicólogo o psiquiatra, sino que existen otras personas a su alrededor en las que pueden apoyarse con los que compartir además procesos ya vividos de los que otros, pueden aprender.

Por último la antipsiquiatría revindica la necesidad de que toda persona con enfermedad mental debería poder llevar una vida lo más normalizada posible, reduciendo al máximo los periodos de hospitalización y focalizando los recursos de atención ambulatoria que permitan a la persona mantener su día a día. Para conseguir que esta libertad comunitaria se dé es imprescindible implicar a la propia comunidad y a las instituciones. Para potenciar este tipo de espacios la experiencia artística debe implicar que las obras sean vistas por la sociedad para conseguir un cambio en el imaginario social. En la experiencia arteterapéutica se ha respetado el encuadre marcado inicialmente, las obras no han salido del espacio arteterapéutico y por tanto no se ha podido comprobar la repercusión de esto. 


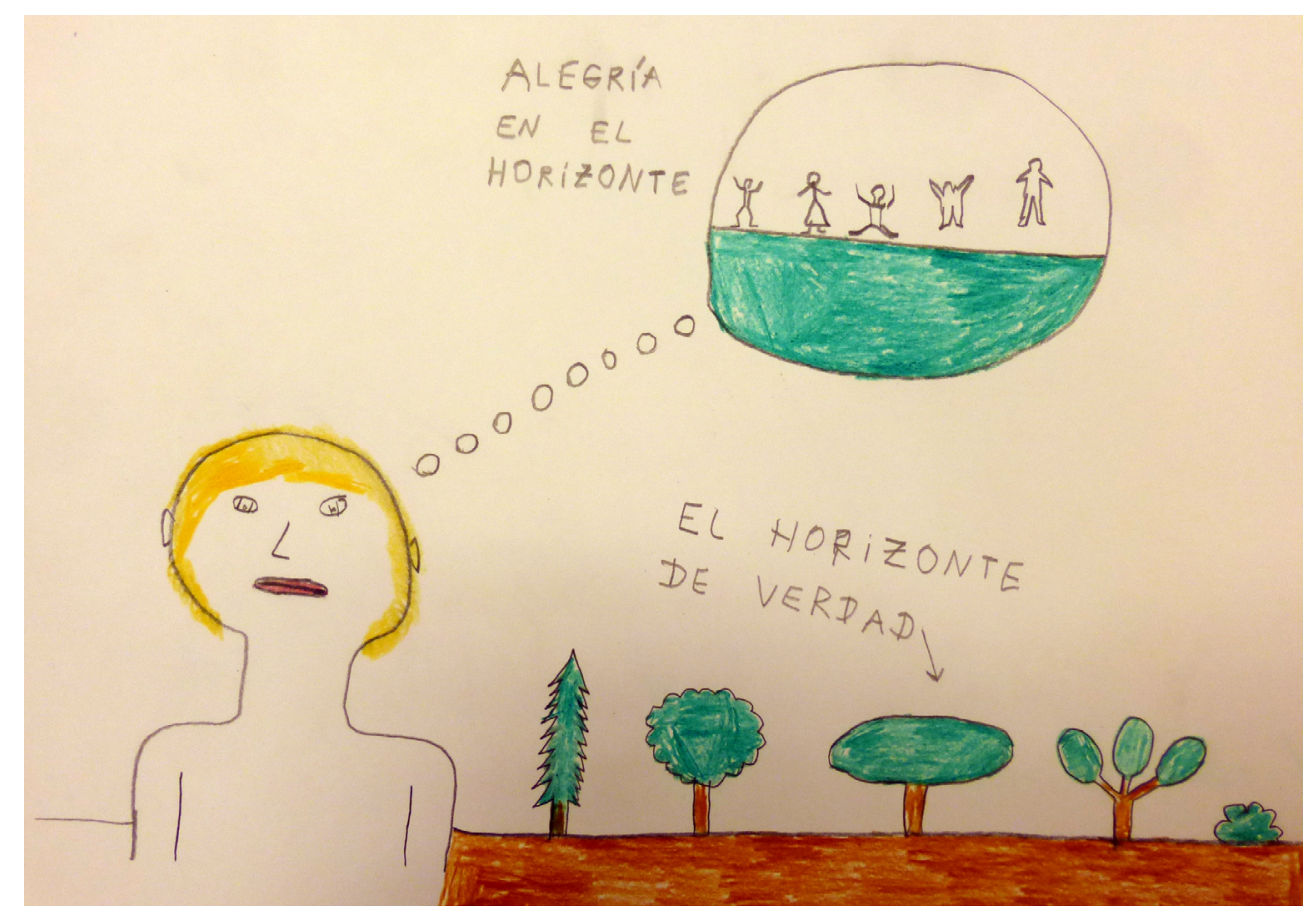

Figura 6. "Alegría en el horizonte", obra realizada por DI. DI representa en su obra el horizonte de verdad y por otro lado el horizonte con el que sueña el ser humano.

Se responde por tanto al objetivo general de este trabajo así como los objetivos específicos. Las necesidades de cambio existen y se hacen reales cuando se da voz a las personas con enfermedad mental, cuando nadie habla a través de ellos, puede por tanto incluirse el Arteterapia entre uno de los recursos o herramientas que puede potenciar estas mejoras, en los que, los participantes, los profesionales de la salud e incluso la sociedad podamos crear entre todos, una realidad distinta.

"La utopía está en el horizonte. Camino dos pasos, ella se aleja dos pasos y el horizonte se corre diez pasos más allá. ¿Entonces para qué sirve la utopía? Para eso sirve, para caminar" (Galeano, 2012).

\section{Referencias}

Arias, M. M. A. (2000). La triangulación metodológica: sus principios, alcances y limitaciones. Investigación y Educación en Enfermería, XVIII(1), 13-26.

Desviat, M. (2006). La antipsiquiatría: crítica a la razón psiquiátrica. Norte de Salud Mental, 6(25), 8-14.
Galeano, E. (2012) ¿Para qué sirve la utopía? [entrevista televisiva realizada por Fernando Birri]. Recuperado a partir de нтtps://www. YOUTUBE.COM/WATCH?V=GARPIBJ5XHO

Hall, W. (2009). Discontinuación del uso de drogas psiquiátricas: Una guía basada en la reducción del daño. Massachussetts: The Icarus Project / Freedom Center. 
Longui, R. (2014, octubre). Presentación académica en la Universidad Autónoma de Madrid. Madrid.

Obiols, J. (1973). Psiquiatría y antipsiquiatría. Barcelona: Salvat.

Olza, I. (2014). Locas [Las voces que hay que oír, alternativas a la psiquiatrización]. Mujeres y Salud, 36, 3-4.
Rey, P. (2014). Entrevista a la princesa Inca. Mujeres $y$ Salud, 36, 11-15.

Sava, A. (2008). Arte y desmanicomialización. Una puerta a la libertad en hospitales psiquiátricos públicos de Argentina. Buenos Aires: Artes Escénicas. 